\title{
Effects of Infiltration Amounts on Preferential Flow Characteristics and Solute Transport in the Protection Forest Soil of Southwestern China
}

\author{
Mingfeng $\mathrm{Li}^{1}{ }^{1}$, Jingjing Yao ${ }^{2}$, Ru Yan ${ }^{1}$ and Jinhua Cheng ${ }^{1, *}$ \\ 1 Jinyun Forest Ecosystem Research Station, School of Soil and Water Conservation, Beijing Forestry University, \\ Beijing 100083, China; m17710660921@163.com (M.L.); yanru2016@163.com (R.Y.) \\ 2 Environmental Protection Research Institute of Light Industry, Research Centre for Urban Environment, \\ Beijing Academy of Science and Technology, Beijing 100095, China; yaojing1989_lucky@163.com \\ * Correspondence: jinhua_cheng@126.com
}

check for

updates

Citation: Li, M.; Yao, J.; Yan, R.; Cheng, J. Effects of Infiltration Amounts on Preferential Flow Characteristics and Solute Transport in the Protection Forest Soil of Southwestern China. Water 2021, 13, 1301. https://doi.org/10.3390/ w13091301

Academic Editors: Domenico Cicchella and Viktor O. Polyakov

Received: 18 February 2021

Accepted: 3 May 2021

Published: 6 May 2021

Publisher's Note: MDPI stays neutral with regard to jurisdictional claims in published maps and institutional affiliations.

Copyright: (c) 2021 by the authors. Licensee MDPI, Basel, Switzerland. This article is an open access article distributed under the terms and conditions of the Creative Commons Attribution (CC BY) license (https:// creativecommons.org/licenses/by/ $4.0 /)$.

\begin{abstract}
Preferential flow has an important role as it strongly influences solute transport in forest soil. The quick passage of water and solutes through preferential flow paths without soil absorption results in considerable water loss and groundwater pollution. However, preferential flow and solute transport under different infiltration volumes in southwestern China remain unclear. Three plots, named P20, P40 and P60, were subjected to precipitation amounts of 20, 40 and $60 \mathrm{~mm}$, respectively, to investigate preferential flow and solute transport characteristics via field multiple-tracer experiments. Stained soils were collected to measure $\mathrm{Br}^{-}$and $\mathrm{NO}_{3}{ }^{-}$concentrations. This study demonstrated that precipitation could promote dye tracer infiltration into deep soils. The dye tracer reached the maximum depth of $40 \mathrm{~cm}$ in P60. Dye coverage generally reduced with greater depth, and sharp reductions were observed at the boundary of matrix flow and preferential flow. Dye coverage peaked at the soil depth of $15 \mathrm{~cm}$ in P40. This result demonstrated that lateral infiltration was enhanced. The long and narrow dye coverage pattern observed in P60 indicated the occurrence of macropore flow. $\mathrm{Br}^{-}$and $\mathrm{NO}_{3}{ }^{-}$were found at each soil depth where preferential flow had moved. Increasing precipitation amounts increased $\mathrm{Br}^{-}$and $\mathrm{NO}_{3}{ }^{-}$concentration and promoted solute movement into deep soil layers. Solute concentration peaked at near the end of the preferential flow path and when preferential flow underwent lateral movement. These results indicated that the infiltration volume and transport capacity of preferential flow had important effects on the distribution of $\mathrm{Br}^{-}$ and $\mathrm{NO}_{3}{ }^{-}$concentrations. The results of this study could help expand our understanding of the effects of preferential flow on solute transport and provide some suggestions for protection forest management in southwestern China.
\end{abstract}

Keywords: multiple-tracer experiments; precipitation amounts; preferential flow; solute transport; protection forest

\section{Introduction}

Preferential flow, considered as a typical soil water movement process in unsaturated soils, has an important influence on water infiltration and solute transport [1-3]. It is a rapid and nonequilibrium process that accounts for $11 \%$ to $54 \%$ of the entire water flow $[4,5]$. Preferential flow can cause water and solutes to rapidly bypass most of the soil matrix through preferential flow paths, which are formed by cracks, biological activities, root channels, erosive actions, soil shrinkage cracking and freezing-thawing phenomena [6-8]. Preferential flow thus drastically decreases the utilisation rate of water and nutrients and positively increases the contamination risks of groundwater [9].

Preferential flow has received considerable attention because it is an important factor that considerably influences water and nutrient transport in rainfall events. It is induced by numerous factors, including soil texture and structure; channels formed by biological 
activities, such as roots and earthworms; crop management; antecedent soil water; rainfall intensity and precipitation $[6,10]$. Soil types and structure have a complex effect on preferential flow because of their spatial heterogeneities, which can directly change the hydraulic properties, quantities and distribution of soil macropores. Soil clay content could change the soil pore structure and thus affect the type of preferential flow occurring in the soil [11]. The greater the clay content in the soil, the more obvious the macropore structure and the more favourable the formation of preferential flow [12,13]. Biological activities create complex channel systems that can serve as preferential flow paths, further influencing the lateral and vertical movements of preferential flow [14]. The role of antecedent soil water in preferential flow may differ under different soil and macropore conditions [15]. The effect of rainfall intensity on preferential flow has been well discussed, and several studies have shown that the proportion of macropore flow usually increases with the increase in rainfall intensity when it is higher than the infiltration rate $[6,10]$. However, preferential flow and its influence on water and solute transport under different precipitation amounts, which can affect soil moisture and soil water repellency during rainfall events, have received limited attention.

Vidon and Cuadra [10] showed that the proportion of the contribution of macropore flow to total flow flux is positively correlated with precipitation amounts. However, the spatial changes shown by preferential flow under different precipitation amounts have not been fully described and quantitatively evaluated. Such information is crucial for understanding the mechanism of preferential flow in different rainfall events. Moreover, identifying the role of preferential flow in solute transport under different precipitation volumes can help reduce groundwater pollution.

Tracing experiments are increasingly used to study preferential flow in the field and laboratory [16,17]. The food-grade dye Brilliant Blue is widely applied to describe preferential flow because of its advantages of low cost, high water solubility, limited toxicity, stability and distinct visibility [15]. However, it cannot describe solute transport during different steps of infiltration. Therefore, multiple-tracer experiments have been gradually performed to characterise preferential flow and solute transport given the similarity of their advantages with those of experiments with Brilliant Blue FCF [1,3]. In these experiments, image processing is used to describe the distribution of preferential flow, and the concentrations of tracer ions are measured to characterise solute transport during infiltration.

The Three Gorges reservoir area is located in the combination of the middle and upper reaches of the Yangtze River, with complex topography, large spatial variation of natural resources and strong anthropogenic interference. It is a sensitive ecological area and an important functional area for soil and water conservation in China. The protection forest optimisation project of nearly 270,000 ha has been implemented to solve the problems of unreasonable spatial distribution and structure of forest species, poor quality of forest stands and low ecological protection effectiveness in the Three Gorges reservoir area of the Yangtze River. However, fertilisers and pesticides are widely applied in the process of optimising the construction of protective forests, which has an impact on the quality of water resources in the Three Gorges reservoir area. High mean annual precipitation reaching $1031 \mathrm{~mm}$ increases groundwater contamination risks in this region [15]. More than $80 \%$ of rainfall is received during April to October, with the region receiving the highest amount of rainfall during June to August. The utilisation rate of water, fertilisers and pesticides may be seriously influenced by preferential flow during these months. In addition, groundwater contamination is promoted by the increase in the amount of solutes that infiltrate deep soil together with preferential flow. Thus, determining preferential flow characteristics and their effect on solute transport under different infiltration amounts is highly desirable. The objective of the present study was to (1) characterise the distribution of preferential flow and (2) determine solute transport with preferential flow under different infiltration amounts via multiple-tracer experiments. 


\section{Materials and Methods}

Field Experiments

Field multiple-tracer experiments were conducted in protection forest soil in Simian Mountain $\left(28^{\circ} 36^{\prime} \mathrm{N}, 106^{\circ} 23^{\prime} \mathrm{E}\right)$, Chongqing Province, Three Gorges Area, China. This area is located at the end of the Three Gorges reservoir area where it has a subtropical humid monsoon climate with $17-19^{\circ} \mathrm{C}$ annual mean temperature and 1000-1250 mm mean annual precipitation received mainly from April to October. According to the Chinese soil taxonomy, the soil type of the study area is yellow earth, which belongs to the class of ferralsols, the subclass of wet-warm ferralsols. To improve the protective forest system, people have been optimising the species and spatial configuration of the protection forests in this region from 2000 to the present. Our study selected the protection forests which were mainly dominated by Cunninghamia lanceolate and Quercus acutissima, and the understory companion plant species include Itea oblonga, Eurga loquaiana, Plagiogyria distinctissima and Aster ageratoides. In the first 3 years, pest and disease control were conducted in the protection forest regularly. The pesticides (Use $0.75 \sim 1 \%$ Bordeaux, $75 \%$ chlorothalonil wettable powder, or $65 \%$ Dyson zinc) were applied during July to August once a week for 3 consecutive weeks, with 50 to $70 \mathrm{~kg}$ of the pesticides per mu. The type of fertiliser, the amount of fertiliser applied, and the time of fertiliser application depend on the actual forest growth.

Undisturbed soil cores with volumes of $100 \mathrm{~cm}^{3}$ and soil samples with weights of approximately $500 \mathrm{~g}$ were collected at the depth intervals of $0-10,10-20,20-30,30-40$, 40-50 and 50-60 for the measurement of soil properties, including soil texture, bulk density, total porosity and organic matter content, in the laboratory. Soil characteristics are listed in Table 1.

Table 1. Soil characteristics of the studied field.

\begin{tabular}{|c|c|c|c|c|c|c|}
\hline Depth (cm) & $\begin{array}{l}\text { Sand Content (\%) } \\
\quad(2-0.02 \mathrm{~mm})\end{array}$ & $\begin{array}{l}\text { Silt Content }(\%) \\
(0.02-0.002 \mathrm{~mm})\end{array}$ & $\begin{array}{l}\text { Clay Content (\%) } \\
(\leq 0.002 \mathrm{~mm})\end{array}$ & $\begin{array}{l}\text { Bulk Density } \\
\left(\mathrm{g} \cdot \mathrm{cm}^{3}\right)\end{array}$ & Total Porosity (\%) & $\begin{array}{c}\text { Organic Matter } \\
\text { Content }(\%)\end{array}$ \\
\hline $0-10$ & $66.33 \pm 6.03$ & $28.76 \pm 1.03$ & $4.91 \pm 0.09$ & $1.05 \pm 0.07$ & $60.30 \pm 8.83$ & $4.78 \pm 0.23$ \\
\hline $10-20$ & $59.34 \pm 3.34$ & $30.67 \pm 0.78$ & $9.99 \pm 0.23$ & $1.13 \pm 0.03$ & $58.15 \pm 3.08$ & $4.33 \pm 0.12$ \\
\hline $20-30$ & $45.32 \pm 2.92$ & $42.19 \pm 2.26$ & $12.49 \pm 0.43$ & $1.22 \pm 0.06$ & $50.95 \pm 1.98$ & $3.21 \pm 0.13$ \\
\hline $30-40$ & $44.32 \pm 3.00$ & $43.18 \pm 2.23$ & $12.50 \pm 0.48$ & $1.30 \pm 0.02$ & $52.20 \pm 1.89$ & $2.56 \pm 0.13$ \\
\hline $40-50$ & $43.21 \pm 4.25$ & $46.03 \pm 1.30$ & $10.76 \pm 0.92$ & $1.29 \pm 0.03$ & $49.36 \pm 1.23$ & $2.01 \pm 0.12$ \\
\hline $50-60$ & $40.45 \pm 3.74$ & $49.06 \pm 3.24$ & $10.49 \pm 0.45$ & $1.27 \pm 0.05$ & $49.71 \pm 0.89$ & $1.54 \pm 0.11$ \\
\hline
\end{tabular}

Note: Data in the table are the average value \pm standard deviation.

In this study, three areas with similar site conditions were selected for the replication of the field multiple-tracer experiments. In each area, three different infiltration levels of 20, 40 and $60 \mathrm{~mm}$ were established to simulate three different infiltration amounts, which were designated as P20, P40 and P60, respectively. Each level had two plots, which were treated with different solutions. A total of 18 plots were established for the six treatments, with each type of treatment having three replicates $(3$ replicates $\times 6$ plots each $=18$ plots total). For each plot, two rectangular iron frames, namely, an inner frame with dimensions of $60 \mathrm{~cm}$ (length) $\times 60 \mathrm{~cm}$ (width) $\times 50 \mathrm{~cm}$ (height) and an outer frame with dimensions of $80 \mathrm{~cm} \times 80 \mathrm{~cm} \times 50 \mathrm{~cm}$, were concentrically embedded into the soil to a depth of $30 \mathrm{~cm}$ after the experimental surface had been cleaned and smoothed. After embedding, the soil within $5 \mathrm{~cm}$ was compacted by using a wooden hammer to prevent dye tracer infiltration along the frames. Due to the relatively high initial water content of the soil in the study area, the accumulation of water will rapidly form on the soil surface layer. Therefore, the solution was quickly applied to the soil surface of the inner frame to simulate instantaneous ponding infiltration. In accordance with double-ring infiltration, the same depth of freshwater was simultaneously applied to the soil surface of the outer frame at each step to force the solution to infiltrate into the inner frame fully. The details of the field multiple-tracer experiments are shown in Figure 1 and Table 2. These details include the layout of the plots, the solute of the solution, the volume of the solution and the time consumed for solution infiltration. The solution from step 2 (3) should be added 
only when the solution from step 1 (2) is completely infiltrated to avoid the mixing of different solutions. The plots were covered with plastic tarpaulin to prevent evaporation and rainfall. After $24 \mathrm{~h}$ from the beginning of the experiment, five vertical slices were excavated from the core region of the dye area to avoid excavating disturbed soil edges. Each vertical slice was spaced $10 \mathrm{~cm}$ apart. A fine mist of a solution of starch $\left(50 \mathrm{~g} \mathrm{~L}^{-1}\right)$ and $\mathrm{Fe}_{2}\left(\mathrm{SO}_{4}\right)_{3}\left(20 \mathrm{~g} \mathrm{~L}^{-1}\right)$ was uniformly sprayed onto the excavated soil surface immediately after a slice was exposed. The solution was an iodide indicator solution and showed a distinct purple colour when it encountered iodine molecules. After sufficient reaction for approximately $10 \mathrm{~min}$, a digital camera $(2560 \times 1960)$ was used to photograph the dye-stained patterns of the horizontal and vertical slices. Colour images were classified as stained or unstained areas in accordance with the procedure of Yao et al. [15]. In this study, each $1 \mathrm{~mm} \times 1 \mathrm{~mm}$ area of the original slice was represented by one pixel. After photography, soil samples weighing approximately $100 \mathrm{~g}$ were collected from the stained area at a site $5 \mathrm{~mm}$ below each excavated soil surface to remove the solution of starch and $\mathrm{Fe}_{2}\left(\mathrm{SO}_{4}\right)_{3}$. These soil samples were collected to measure the concentrations of $\mathrm{Br}^{-}$ and $\mathrm{NO}_{3}{ }^{-}$. The initial concentrations of $\mathrm{Br}^{-}$in the soil were ignored because they were significantly lower than the applied concentrations. The concentration of $\mathrm{NO}_{3}{ }^{-}$in plot 1 was considered as the initial concentration of $\mathrm{NO}_{3}{ }^{-}$in the soil.

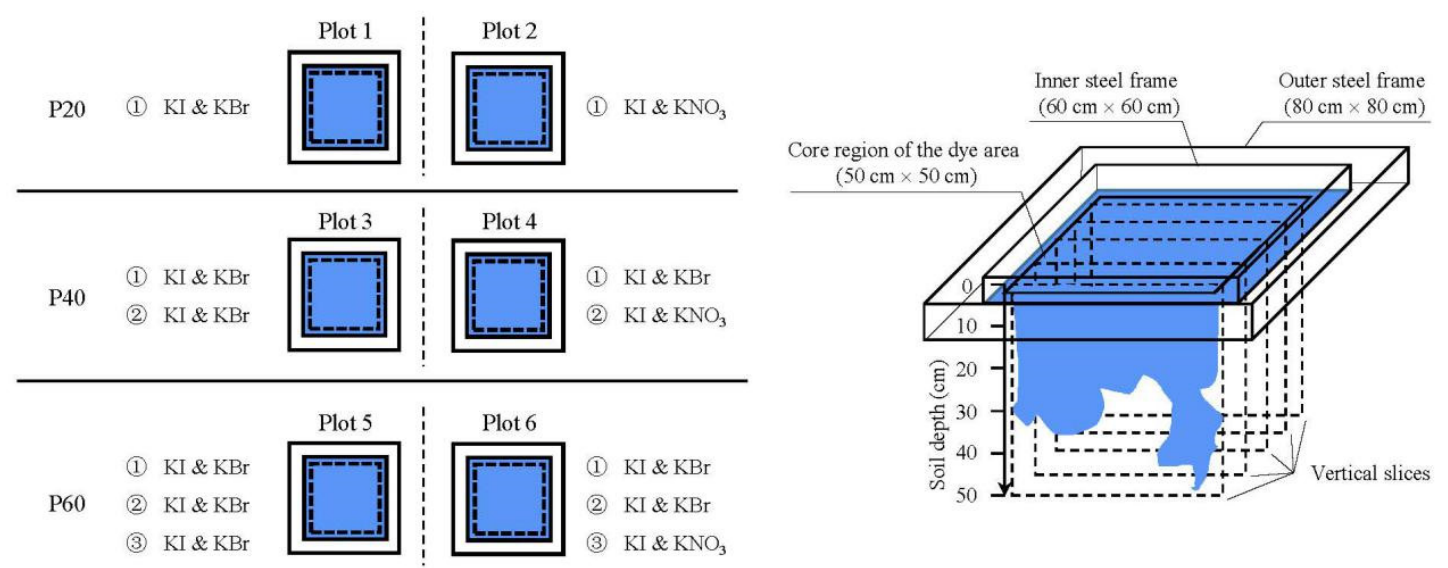

Figure 1. Diagram of the experimental set-up for multiple-tracer experiments.

Table 2. Periods of each step for P20, P40 and P60.

\begin{tabular}{ccccc}
\hline Level & Plots & $\begin{array}{c}\text { Sequence of Matrix } \\
\text { Solution Application }\end{array}$ & $\begin{array}{c}\text { Total Applied Solution } \\
\text { Amount (mm) }\end{array}$ & $\begin{array}{c}\text { Period of Mixture Solution } \\
\text { Infiltration (min) }\end{array}$ \\
\hline \multirow{2}{*}{ P20 } & Plot 1 & $\mathrm{KI}+\mathrm{KBr}$ & 20 & 13 \\
& Plot 2 & $\mathrm{KI}+\mathrm{KNO}$. & 20 & 15 \\
P40 & Plot 3 & $\mathrm{KI}+\mathrm{KBr} \rightarrow \mathrm{KI}+\mathrm{KBr}$ & 40 & $17 \rightarrow 44$ \\
& Plot 4 & $\mathrm{KI}+\mathrm{KBr} \rightarrow \mathrm{KI}+\mathrm{KNO} 3$ & 40 & $20 \rightarrow 39$ \\
$\mathrm{P} 60$ & Plot 5 & $\mathrm{KI}+\mathrm{KBr} \rightarrow \mathrm{KI}+\mathrm{KBr} \rightarrow \mathrm{KI}+\mathrm{KBr}$ & 60 & $14 \rightarrow 38 \rightarrow 35$ \\
& Plot 6 & $\mathrm{KI}+\mathrm{KBr} \rightarrow \mathrm{KI}+\mathrm{KBr} \rightarrow \mathrm{KI}+\mathrm{KNO}_{3}$ & 60 & $15 \rightarrow 45 \rightarrow 40$ \\
\hline
\end{tabular}

Note: $\mathrm{KI}+\mathrm{KBr}$ : Solution of $\mathrm{KI}\left(20 \mathrm{~g} \mathrm{~L}^{-1}\right)$ and $\mathrm{KBr}\left(10 \mathrm{~g} \mathrm{~L}^{-1}\right) ; \mathrm{KI}+\mathrm{KNO}_{3}$ : Solution of $\mathrm{KI}\left(20 \mathrm{~g} \mathrm{~L}^{-1}\right)$ and $\mathrm{KNO}_{3}\left(10 \mathrm{~g} \mathrm{~L}^{-1}\right)$.

\section{Results and Discussion}

\subsection{Spatial Variation Characteristics of Preferential Flow}

We compared and calculated the data extracted from vertical sections under different infiltration amounts. The dye coverage distributions and the images of dye flow patterns in vertical sections are shown in Figure 2. The nonuniform or dissimilar distributions of dye areas under different infiltration amounts suggested that different preferential flow patterns had developed. As shown in Figure 2, most of the vertical slices were stained with a dye coverage of more than $80 \%$ in the topsoil, indicating that the topsoil experienced 
matrix flow [15,18]. Meanwhile, the matrix flow depths for P20 (Figure 2a), P40 (Figure 2b) and P60 (Figure 2c) were 1.6, 7 and $9.3 \mathrm{~cm}$. These results were similar to the conclusion of a study in plantation forests in the southwest karst region [19], which has shown that the depth of matrix flow increased with the increase in infiltration amounts. The increase in infiltration water corresponded to a longer rainfall period, increasing the potential energy of water supply, and the increase in water potential gradient increased the uniform infiltration of soil water. Additionally, the increase in infiltration water increased the water content in the lower soil layer, slowed down the rate of water infiltration, and promoted the lateral movement of water in the top soil layer to form matrix flow [20].

(a)

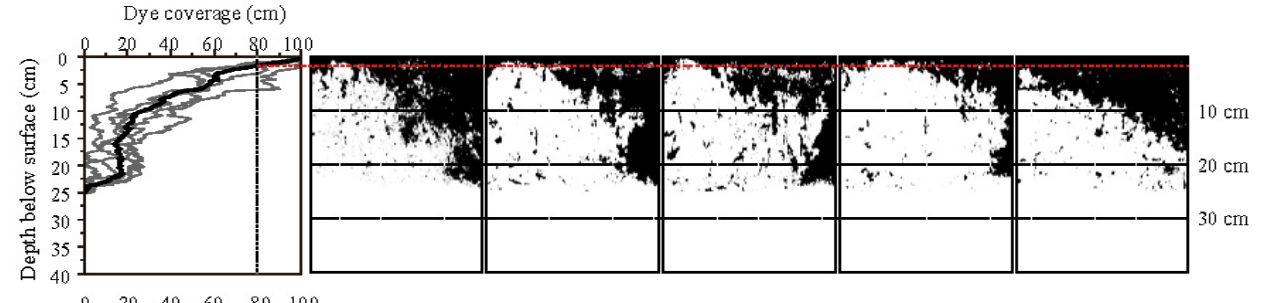

(b)

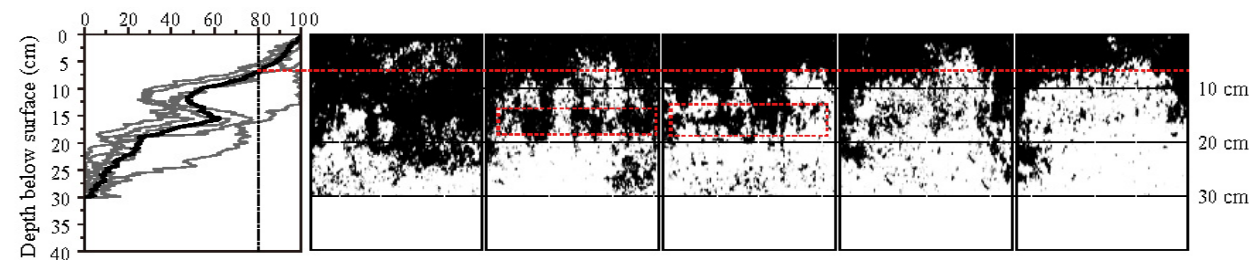

(c)

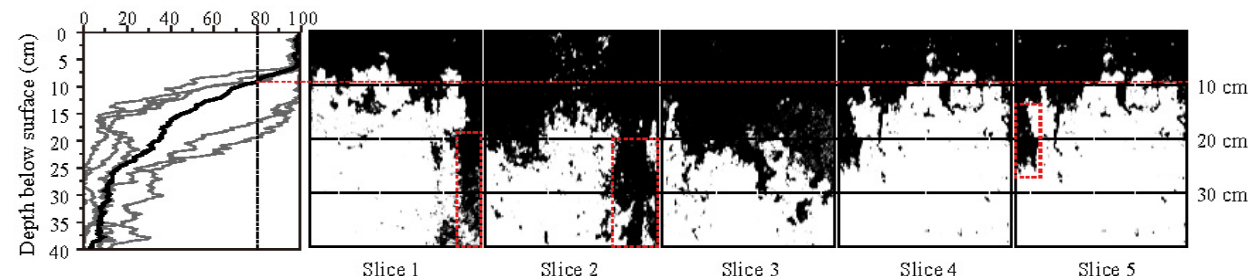

Figure 2. Images showing vertical slices from the dye-stained soil profiles and average dye coverage of vertical slices with depth under different water amounts: (a) 20, (b) 40 and (c) $60 \mathrm{~mm}$.

Due to the increased depth of matrix flow, it was also expected that dye would infiltrate deeper under the higher infiltration amounts. Indeed, our results showed that the maximum infiltration depths for P20, P40 and P60 were 25, 30 and $40 \mathrm{~cm}$, respectively. The consistency of these results with the findings of several other researchers $[20,21]$ indicated the extensive variation range of the movement of the water in the soil under high infiltration amounts. However, our results showed that the matrix flow depth and the maximum infiltration depth occurred in deeper soil layers compared to the study in the plantation forests in the southwest karst region. This could be due to the fact that the sand content and total soil porosity in the soils of our study area $(66.33 \% ; 60.30 \%)$ were higher than those of the above study area $(27.59 \% ; 37.91 \%)$. Previous studies have reported that water movement in clay soils was dominated by preferential flow with less matrix flow compared to loamy soils, as the clay soils were fine-textured and well-structured and were more conducive to the presence of macropores. Additionally, Yan [22] also found that the matrix flow depth was $12 \mathrm{~cm}$ and the maximum infiltration depth was $28 \mathrm{~cm}$ in sandy soils with a sand content of about $80 \%$. Therefore, in future studies of preferential flow, the depth of occurrence of preferential flow and the maximum depth of infiltration could be predicted based on soil conditions and infiltration amounts.

In our study, infiltration amounts had a substantial effect on the spatial heterogeneities of preferential flow despite the similar properties of the three plots (Figure 2). Reductions in the patterns of dye coverage showed different trends amongst P20, P40 and P60. Compared with that in P40 and P60, which showed considerably different patterns amongst vertical slices with the reduction in depth, the pattern of decrement in P20 showed no 
evident change, indicating small spatial heterogeneity (Figure 2a). This result may be attributed to the small depth of matrix flow that lacked sufficient head pressure to allow the formation of preferential flow path networks. Thus, the dye tracer infiltrated into deep soil layers only through a small part of preferential flow paths under low infiltration. In $\mathrm{P} 40$, unexpected increases in dye coverage were detected as the soil depth increased to $15 \mathrm{~cm}$ in P40, demonstrating that high amounts of the dye tracer had infiltrated into these layers (Figure $2 b$ ). Therefore, lateral preferential flow became increasingly evident with the increase in infiltration amount because the infiltration amount exceeded the capacity for the vertical transport of the preferential flow to block preferential flow paths. This phenomenon could also be associated with preferential flow path characteristics, resulting in the high lateral movement of the dye tracer. Root channels are considered as primary preferential flow paths in forest soils $[9,23]$. An investigation into the root systems in the study area revealed that the total root length of the root with root diameter $<1 \mathrm{~mm}$ in the $10-20 \mathrm{~cm}$ soil layers was greater than that in the other soil layers except topsoil $(0-5 \mathrm{~cm})$ (Table 3). Consequently, in this region, the large number of intricate root distributions affected the connectivity of priority flow paths and thus increased lateral preferential flow along root channels. The dye coverage distribution in P60 was consistent with that in P20. Specifically, it lacked a peak and decreased gradually with soil depth. The dye coverage in the vertical slices from P60 had large standard deviations. Three of the five dyed coverage distribution curves showed sharp reductions in the $10-15 \mathrm{~cm}$ soil layers and an obvious trailing phenomenon at the soil depths of $15-40 \mathrm{~cm}$, indicating the existence of penetrating macropore flow (Figure 2c). This result was largely explained by the fact that the increasing amount of infiltration increased the head pressure of the preferential flow. This effect then prompted the formation of the preferential flow network and increased the connectivity of the preferential flow network. In this case, the transport patterns of preferential flow could be divided into two types under the influence of spatial heterogeneity caused by soil texture and roots and biological activities [24,25]. In one case, preferential flow paths were connected vertically to form macropores, and water was transported rapidly through macropores to deep soil layers, thus bypassing most of the soil matrix. By contrast, in the absence of macropores, the unstable wetting front continued to expand because the infiltration rate was lower than the saturated hydraulic conductivity of the soil. This result, in turn, led to the finger-like preferential flow pattern of water and solutes. At the same time, as the infiltration amount was increased, the flow pattern transformed from one dominated by preferential flow to one dominated by matrix flow. Furthermore, macropore flow and finger-like flow appeared as illustrated in Figure 2. The appearance of these flows provided support for the above explanation.

Table 3. Root length $(\mathrm{cm})$.

\begin{tabular}{|c|c|c|c|c|c|}
\hline \multirow{2}{*}{ Soil Depth (cm) } & \multicolumn{5}{|c|}{ Root Diameter } \\
\hline & $<1 \mathrm{~mm}$ & $1-3 \mathrm{~mm}$ & 3-5 mm & 5-10 mm & $>10 \mathrm{~mm}$ \\
\hline $0-5$ & $2549 \pm 322$ & $1284 \pm 211$ & $499 \pm 142$ & $125 \pm 23$ & $19 \pm 12$ \\
\hline $5-10$ & $1504 \pm 97$ & $528 \pm 200$ & $139 \pm 53$ & $54 \pm 8$ & $20 \pm 11$ \\
\hline $10-15$ & $2058 \pm 88$ & $426 \pm 44$ & $149 \pm 40$ & $138 \pm 22$ & $38 \pm 10$ \\
\hline $15-20$ & $2068 \pm 282$ & $394 \pm 86$ & $189 \pm 40$ & $104 \pm 58$ & $23 \pm 10$ \\
\hline $20-25$ & $720 \pm 182$ & $476 \pm 112$ & $111 \pm 62$ & $87 \pm 54$ & $38 \pm 13$ \\
\hline $25-30$ & $565 \pm 300$ & $212 \pm 0$ & $243 \pm 13$ & $44 \pm 0$ & $0 \pm 0$ \\
\hline $30-35$ & $373 \pm 58$ & $396 \pm 58$ & $158 \pm 31$ & $27 \pm 1$ & $0 \pm 0$ \\
\hline $35-40$ & $366 \pm 21$ & $122 \pm 6$ & $48 \pm 6$ & $0 \pm 0$ & $0 \pm 0$ \\
\hline
\end{tabular}

Note: In each soil layer, the root length under different root diameter ranges is the sum of the root length of that root diameter, and the volume of each soil layer is $125 \mathrm{~cm}^{3}$.

Combining these results, the soil in the study area was dominated by sandy loam, and when the infiltration was less than $60 \mathrm{~mm}$, the occurrence of preferential flow could increase the connectivity of soil pores and enhance the water retention capacity of the soil. However, when the infiltration was greater than $60 \mathrm{~mm}$, macropore flow might be 
formed, which would transport water directly to the deeper soil layers to reduce the water utilisation rate, increase the risk of groundwater contamination and possibly reduce the stability of the soil body to induce geological disasters such as landslides.

\subsection{Effect of Preferential Flow on Solute Transport}

The occurrence and development of preferential flow have an important effect on water and solute transport [26]. $\mathrm{Br}^{-}$and $\mathrm{NO}_{3}{ }^{-}$were mixed with $\mathrm{KI}$ separately and infiltrated at different stages to investigate the effect of different infiltration amounts on solute transport. The detailed process of this experiment was performed in accordance with reference methods. The concentration distributions of applied $\mathrm{Br}^{-}$and $\mathrm{NO}_{3}{ }^{-}$in P20, P40 and P60 are shown in Figures 3 and 4. The infiltration depths of the $\mathrm{Br}^{-}$and $\mathrm{NO}_{3}{ }^{-}$solutes were almost identical with those of preferential flow and increased with the increase in infiltration water volume. These results were consistent with the findings of earlier studies showing that soil-water movement depends strongly on rain intensity [27]. However, the different distributions of $\mathrm{Br}^{-}$and $\mathrm{NO}_{3}{ }^{-}$concentrations after the experiment suggested that different types of preferential flows had different effects on solute transport (Figures 3 and 4).

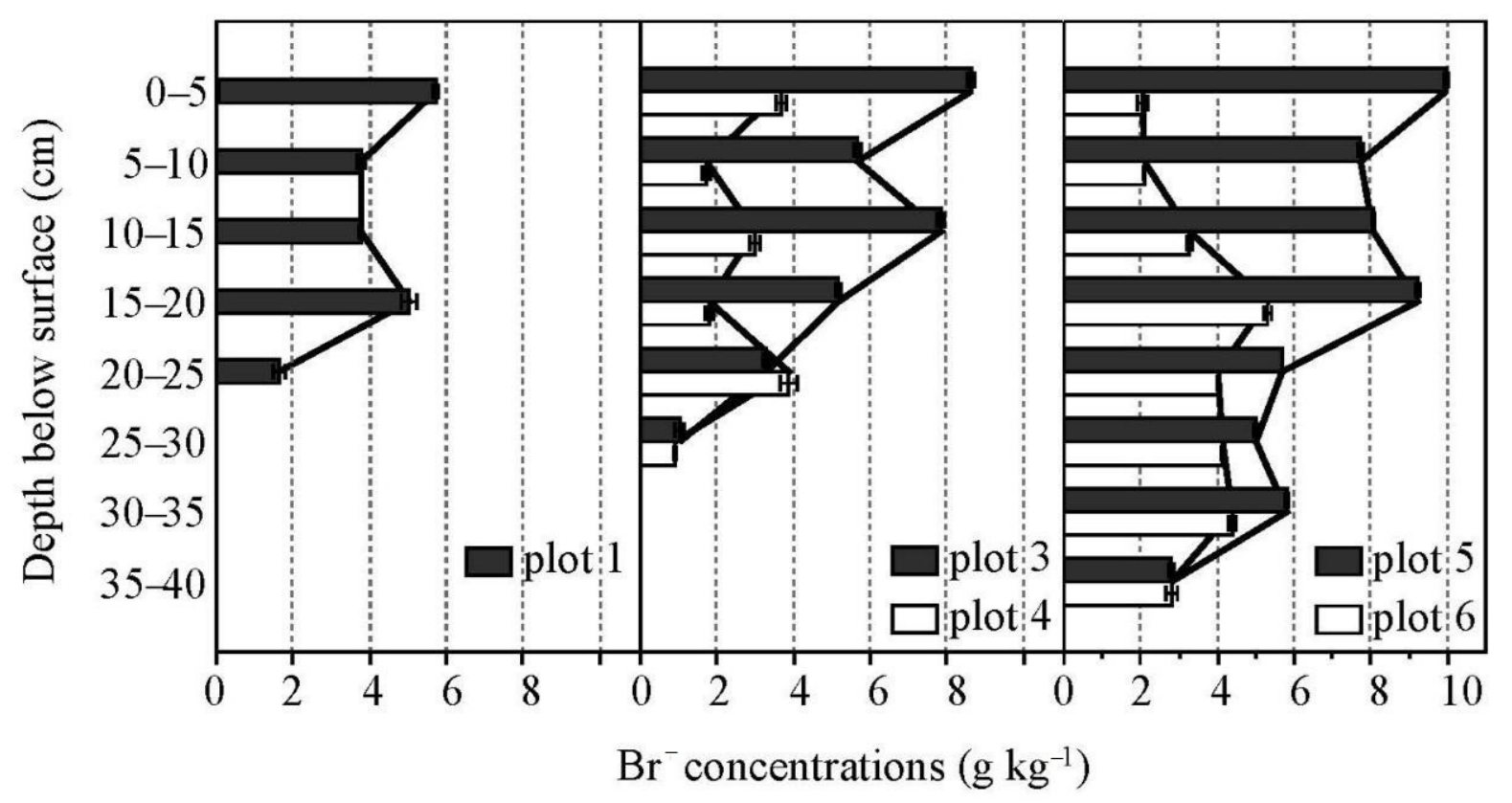

Figure 3. Changes in $\mathrm{Br}^{-}$concentration with soil depth.

As shown in Figure 3, the concentration of $\mathrm{Br}^{-}$at $0-40 \mathrm{~cm}$ soil depth under different infiltration intensities followed the order of plot $5>$ plot $3>$ plot 1 , suggesting that increases in infiltration could increase in concentration. Additionally, in these plots, $\mathrm{Br}^{-}$ concentration distributions displayed small, $\mathrm{W}$-shaped serrated patterns with the increase in soil depth and were highest in the topsoil layer. In other words, the $\mathrm{Br}^{-}$concentration distributions in these plots showed similar trends and decreased with soil depth but peaked in different soil layers. In plot $1, \mathrm{Br}^{-}$concentration peaked at the soil depth of $20 \mathrm{~cm}$. In plot $3, \mathrm{Br}^{-}$concentration peaked at the soil depth of $15 \mathrm{~cm}$ and then again at $25 \mathrm{~cm}$. In plot 5, the first peak of the $\mathrm{Br}^{-}$concentration was observed at the soil depth of $20 \mathrm{~cm}$ and the second at the soil depth of $35 \mathrm{~cm}$. These results indicated that with the increase in infiltration amount, the peak of $\mathrm{Br}^{-}$concentration appeared in deep soil layers and at near the end of the preferential flow. The last peak of $\mathrm{Br}^{-}$concentration observed in each plot was most likely attributed to the solution reaching the end of the preferential flow paths where accumulation occurred and the wetting fronts continued to extend to the surrounding area [28]. Consequently, high $\mathrm{Br}^{-}$concentration was found at about $5 \mathrm{~cm}$ 
before the maximum infiltration soil depth. The other peaks might be attributed to the fact that when the upper infiltration water volume was increased to $40 \mathrm{~mm}$ and $60 \mathrm{~mm}$, infiltration exceeded the capacity for the vertical transport of preferential flow, resulting in the accumulation of water and the development of lateral infiltration. Dye coverage in the layer where the peak was higher than that in other layers also supported this interpretation (Figure 2), suggesting that the distribution pattern of preferential flow was the key to influencing solute transport.

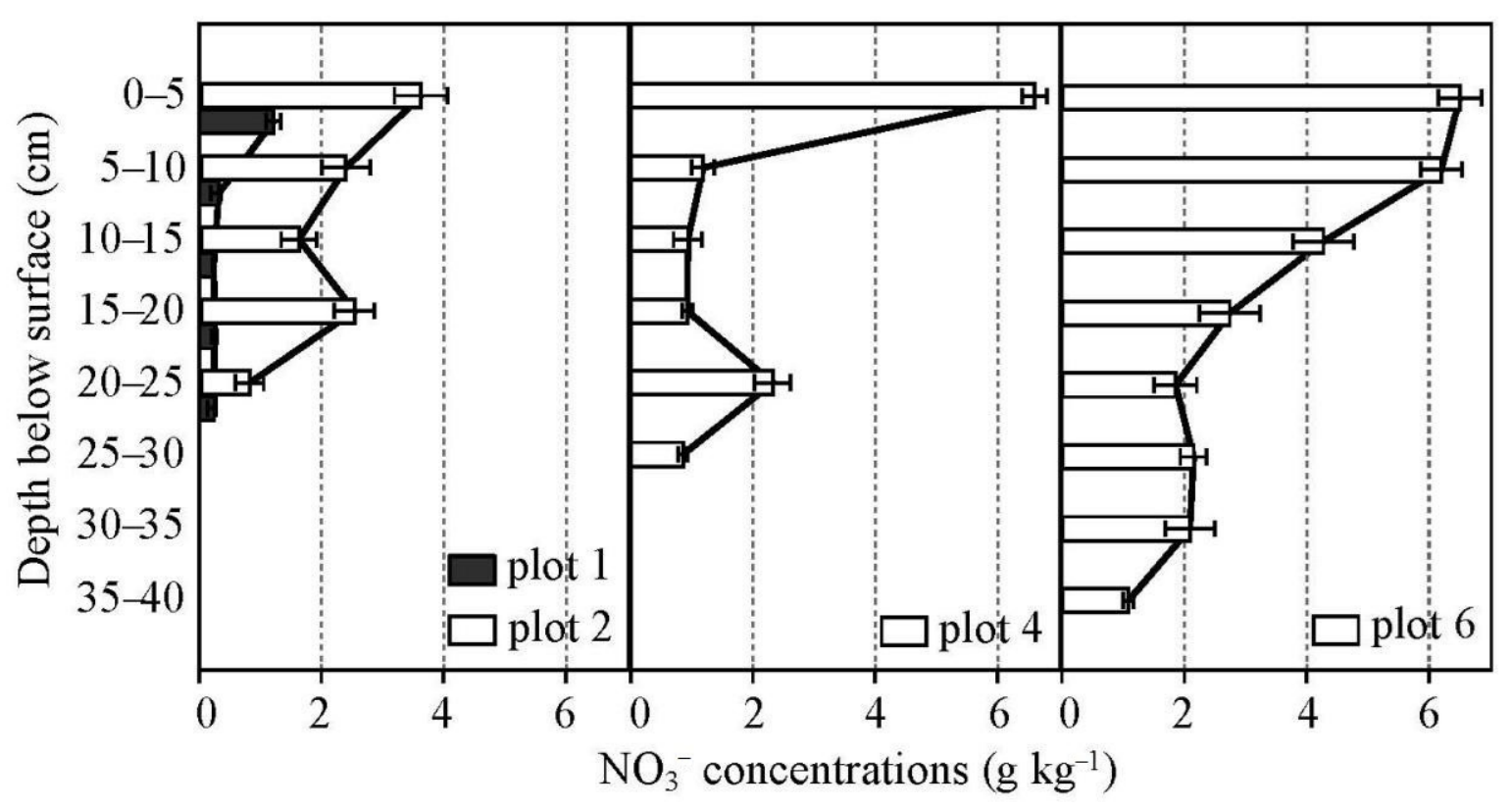

Figure 4. Changes in $\mathrm{NO}_{3}{ }^{-}$concentration with soil depth.

In comparison to plot 3 and plot 5, plot 4 and plot 6 used the solutions of $\mathrm{KI}$ and $\mathrm{KNO}_{3}$ instead of $\mathrm{KI}$ and $\mathrm{KBr}$ in the final infiltration phase. The main purpose of this measure was to analyse the effect on the $\mathrm{Br}^{-}$concentration in the soil for infiltration volumes of 20-40 mm and 40-60 mm, respectively. As shown in Figure 3, the concentration of $\mathrm{Br}^{-}$in plot 4 was similar to that in plot 3 , indicating that the infiltration volume of $20-40 \mathrm{~mm}$ did not change the distribution of $\mathrm{Br}^{-}$concentration. The distribution of $\mathrm{Br}^{-}$concentration in plot 6 was significantly different from that in the preferential flow dyeing area. In plot 6 , unexpected increases in $\mathrm{Br}^{-}$concentration were detected as the soil depth increased from $0 \mathrm{~cm}$ to 20, demonstrating that a large amount of $\mathrm{Br}^{-}$in the surface layer was transported to the deeper soil by the preferential flow when the infiltration volume was at $40-60 \mathrm{~mm}$. These results indicated that the solution from the second stage of infiltration mixed with the solution from the first stage of infiltration in the soil and transported downward. The third stage of infiltration pushed the pre-infiltrated solution downward with little interaction (as an approximately piston flow) at depths of $0-10 \mathrm{~cm}$ soil layers, probably because the first two stages of infiltration made the soil water saturated.

The $\mathrm{NO}_{3}{ }^{-}$concentrations in plot 2, plot 4 and plot 6 represented the distribution of $\mathrm{NO}_{3}{ }^{-}$at $0-20 \mathrm{~mm}, 20-40 \mathrm{~mm}$ and $40-60 \mathrm{~mm}$ of infiltration water, respectively (Figure 4). The $\mathrm{NO}_{3}{ }^{-}$concentration shown in plot 1 was the original soil $\mathrm{NO}_{3}{ }^{-}$content when the $\mathrm{NO}_{3}{ }^{-}$-containing tracer was not added. The original $\mathrm{NO}_{3}{ }^{-}$concentration in the soil was low and therefore had a slight influence on the distribution of $\mathrm{NO}_{3}{ }^{-}$concentration in the solute transport experiments. The pattern of $\mathrm{NO}_{3}{ }^{-}$concentration in plot 2 was consistent with that of $\mathrm{Br}^{-}$concentration in plot 1 . This result indicated the absence of a significant difference in the concentration distribution of different solutes transported with preferential flow under a $20 \mathrm{~mm}$ infiltration volume. This is consistent with other studies that have shown rapid downward transport of water through the native preferential flow paths at low 
infiltration volume [21,22]. The significantly lower concentration of $\mathrm{NO}_{3}{ }^{-}$than that of $\mathrm{Br}^{-}$ at an infiltration of $20 \mathrm{~mm}$ may be attributed to the fact that $\mathrm{NO}_{3}{ }^{-}$is more readily available to plants and microorganisms than $\mathrm{Br}^{-}$and converted into other forms, such as $\mathrm{N}_{2}$ and $\mathrm{NH}_{4}{ }^{+}$. In plot 4, the highest $\mathrm{NO}_{3}{ }^{-}$concentration was detected in the topsoil, and $\mathrm{NO}_{3}{ }^{-}$ concentration in other soil layer was significantly lower than that in plot 2, suggesting that the second stage solution was mainly concentrated on the soil surface and did not transport to deeper soil layers with the preferential flow. In plot 6, $\mathrm{NO}_{3}{ }^{-}$concentration decreased with the increase in soil layers without significant peaks. This result was consistent with previous studies indicating that increasing infiltration reduced the capillary effect of the soil layer and promoted the vertical connectivity of preferential flow paths, resulting in rapid solute transport to deep layers $[1,29,30]$. However, differently from previous studies, there were no peaks observed in this study and the $\mathrm{NO}_{3}{ }^{-}$concentration in plot 6 was significantly higher than that in plot 4 , suggesting that the solute infiltration process in the third stage was accumulated and rapidly transported. This result may be due to the fact that when the amounts of infiltration volume reached a certain threshold, the formation of a penetrating macropore flow promoted the downward transport of solutes and reduced lateral infiltration.

These observations suggested that when the amount of water infiltration exceeded $40 \mathrm{~mm}$, preferential flow infiltration depth and development increased, and solutes could infiltrate into deep soil layers along with macropore preferential flow during rainfall events. Therefore, in the future management of protective forest cultivation, fertiliser application and pesticide spraying before rain storms should be avoided as much as possible in order to reduce the pollution of shallow groundwater by pesticides and nutrients, etc.

\section{Conclusions}

Our results indicated that infiltration amounts significantly affected dye flow patterns and infiltration depth. When the infiltration volume was less than $40 \mathrm{~mm}$, further increasing infiltration amounts increased the lateral infiltration of preferential flow and increased solute concentration. When the infiltration volume exceeded $40 \mathrm{~mm}$, increasing infiltration amounts resulted in the development of highly continuous and effective preferential flow paths and increased the amount of solutes transported to deep soil layers through macropores. The results shown in this study could provide some suggestions for protected forest management and preferential flow hazard reduction. Nevertheless, the scale of this study was small, and the results might be influenced by soil heterogeneity. Further research should combine solute transport models with field tracing experiments to explore largescale preferential flow and solute transport characteristics during natural rainfall events.

Author Contributions: Conceptualisation, M.L. and J.Y; methodology, M.L., R.Y. and J.Y.; software, M.L.; validation, M.L. and J.Y; formal analysis, M.L., R.Y. and J.C.; investigation, M.L. and J.Y; resources, M.L., R.Y. and J.C.; data curation, M.L.; writing—original draft preparation, M.L., J.C., R.Y. and J.Y.; writing-review and editing, M.L. and J.Y.; visualisation, M.L. and J.Y; supervision, M.L. and J.Y; project administration, M.L.; funding acquisition, M.L., R.Y. and J.C. All authors have read and agreed to the published version of the manuscript.

Funding: This research was funded by the National Science and Technology Major Project (2018 ZX07101005) and the National Natural Science Foundation of China (32071839).

Institutional Review Board Statement: No studies involving humans or experimental animals were conducted in this research.

Informed Consent Statement: No studies involving humans or experimental animals were conducted in this research.

Data Availability Statement: The data presented in this study are available on request from the corresponding author. The data are not publicly available due to privacy or ethical restrictions. 
Acknowledgments: Many thanks to the Forest Management Station of Simian Mountain for offering accommodations and supporting field experiments. We also gratefully acknowledge the editor and reviewers.

Conflicts of Interest: The authors declare no conflict of interest.

\section{References}

1. Wang, K.; Zhang, R. Heterogeneous soil water flow and macropores described with combined tracers of dye and iodine. J. Hydrol. 2011, 397, 105-117. [CrossRef]

2. Nimmo, J.R. Preferential flow occurs in unsaturated conditions. Hydrol. Process. 2012, 26, 786-789. [CrossRef]

3. Sheng, F.; Liu, H.; Kang, W.; Zhang, R.; Tang, Z. Investigation into preferential flow in natural unsaturated soils with field multiple-tracer infiltration experiments and the active region model. J. Hydrol. 2014, 508, 137-146. [CrossRef]

4. Legout, A.; Legout, C.; Nys, C.; Dambrine, E. Preferential flow and slow convective chloride transport through the soil of a forested landscape (Fougères, France). Geoderma 2009, 151, 179-190. [CrossRef]

5. Heijdena, G.d.; Legouta, A.; Polliera, B.; Bréchetb, C.; Rangera, J.; Dambrinec, E. Tracing and modeling preferential flow in a forest soil-Potential impact on nutrient leaching. Geoderma 2013, 195-196, 12-22. [CrossRef]

6. Jarvis, N.J. A review of non-equilibrium water flow and solute transport in soil macropores: Principles, controlling factors and consequences for water quality. Eur. J. Soil Sci. 2007, 58, 523-546. [CrossRef]

7. Forsmann, D.M.; Kjaergaard, C. Phosphorus release from anaerobic peat soils during convective discharge-Effect of soil Fe:P molar ratio and preferential flow. Geoderma 2014, 223-225, 21-32. [CrossRef]

8. Alaoui, A. Modelling susceptibility of grassland soil to macropore flow. J. Hydrol. 2015, 525, 536-546. [CrossRef]

9. Yi, J.; Yang, Y.; Liu, M.; Hu, W.; Zhang, D. Characterising macropores and preferential flow of mountainous forest soils with contrasting human disturbances. Soil Res. 2019, 57, 601-614. [CrossRef]

10. Vidon, P.; Cuadra, P.E. Impact of precipitation characteristics on soil hydrology in tile-drained landscapes. Hydrol. Process. 2010, 24, 1821-1833. [CrossRef]

11. Sheng, F.; Kang, W.; Zhang, R.; Liu, H. Characterizing soil preferential flow using iodine-starch staining experiments and the active region model. J. Hydrol. 2009, 367, 115-124. [CrossRef]

12. Chen, X.; Cheng, J. Application of Landscape Pattern Analysis to Quantitatively Evaluate the Spatial Structure Characteristics of PreferentialFlow Paths in Farmland. Appl. Eng. Agric. 2016, 32, 203-215. [CrossRef]

13. Grant, K.N.; Macrae, M.L.; Ali, G.A. Differences in preferential flow with antecedent moisture conditions and soil texture: Implications for subsurface P transport. Hydrol. Process. 2019, 33, 2068-2079. [CrossRef]

14. Murielle, G.; Sidle, R.C.; Alexia, S. The Influence of Plant Root Systems on Subsurface Flow: Implications for Slope Stability. BioScience 2011, 61, 869-879. [CrossRef]

15. Yao, J.; Cheng, J.; Sun, L.; Zhang, X.; Zhang, H. Effect of Antecedent Soil Water on Preferential Flow in Four Soybean Plots in Southwestern China. Soil Sci. 2017, 182, 1. [CrossRef]

16. Mooney, S.J.; Morris, C. A morphological approach to understanding preferential flow using image analysis with dye tracers and X-ray Computed Tomography. Catena 2008, 73, 204-211. [CrossRef]

17. Wang, F.; Chen, H.; Lian, J.; Fu, Z.; Nie, Y. Preferential Flow in Different Soil Architectures of a Small Karst Catchment. Vadose Zone J. 2018, 17, 2-10. [CrossRef]

18. Bargués Tobella, A.; Reese, H.; Almaw, A.; Bayala, J.; Malmer, A.; Laudon, H.; Ilstedt, U. The effect of trees on preferential flow and soil infiltrability in an agroforestry parkland in semiarid Burkina Faso. Water Resour. Res. 2014, 50, 3342. [CrossRef] [PubMed]

19. Kan, X.; Cheng, J.; Hou, F. Response of Preferential Soil Flow to Different Infiltration Rates and Vegetation Types in the Karst Region of Southwest China. Water 2020, 12, 1778. [CrossRef]

20. Hardie, M.; Doyle, R.; Cotching, W.; Holz, G.; Lisson, S. Hydropedology and Preferential Flow in the Tasmanian Texture-Contrast Soils. Vadose Zone J. 2013, 12, 108-112. [CrossRef]

21. Markus, W.; Felix, N. An experimental tracer study of the role of macropores in infiltration in grassland soils. Hydrol. Process. 2003, 17, 477-493. [CrossRef]

22. Yan, J.; Zhao, W. Characteristics of preferential flow during simulated rainfall events in an arid region of China. Environ. Earth Sci. 2016, 75, 566. [CrossRef]

23. Luo, Z.; Niu, J.; Xie, B.; Zhang, L.; Zhu, S. Influence of Root Distribution on Preferential Flow in Deciduous and Coniferous Forest Soils. Forests 2019, 10, 986. [CrossRef]

24. Pan, W.; Xu, Y.; Liu, Y.; Gao, L.; Yao, X. Quantitative determination of preferential flow characteristics of loess based on nonuniformity and fractional dimension. Trans. CSAE 2017, 33, 140-147. [CrossRef]

25. Schaik, N.L.M.B.V. Spatial variability of infiltration patterns related to site characteristics in a semi-arid watershed. Catena 2009, 78, 36-47. [CrossRef]

26. Makowski, V.; Julich, S.; Feger, K.H.; Breuer, L.; Julich, D. Leaching of dissolved and particulate phosphorus via preferential flow pathways in a forest soil: An approach using zero-tension lysimeters. J. Plant. Nutr. Soil Sci. 2020, 183, 238-247. [CrossRef]

27. Wu, Q.; Zhang, J.; Lin, W.; Wang, G. Appling dyeing tracer to investigate patterns of soil water flow and quantify preferential flow in soil columns. Trans. CSAE 2014, 30, 82-90. [CrossRef] 
28. Ghafoor, A.; Koestel, J.; Larsbo, M.; Moeys, J.; Jarvis, N. Soil properties and susceptibility to preferential solute transport in tilled topsoil at the catchment scale. J. Hydrol. 2013, 492, 190-199. [CrossRef]

29. Wang, W.; Zhang, H.; Li, M.; Cheng, J.; Lu, W. Infiltration characteristics of water in forest soils in the Simian mountains, Chongqing City, southwestern China. Front. For. China 2009, 4, 338-343. [CrossRef]

30. Kramers, G.; Richards, K.G.; Holden, N.M. Assessing the potential for the occurrence and character of preferential flow in three Irish grassland soils using image analysis. Geoderma 2009, 153, 362-371. [CrossRef] 